\title{
STRATEGI PERANCANGAN REBRANDING KABUPATEN TUBAN YANG MEMILIKI POTENSI RELIGI, BUDAYA DAN SEJARAHNYA
}

\author{
Aileena Solicitor C.R.E.C*, Fitria Ramadhani*, Faisal Ilham P.*, Mohammad Hafil P.*, \\ Daniel Putera N.*, Vidya Nizka P.*
}

*Progdi Desain Komunikasi Visual, Fakultas Arsitektur dan Desain Universitas Pembangunan Nasional Veteran Jawa Timur

E-mail :aileena.dkv@upnjatim.ac.id, fit.fitria99@gmail.com

\begin{abstract}
City branding is a means for an area or city to introduce their potential to the outside community and their own communities so that it can be preserved for the future. Tuban District, which is known by the community today is a producing district of Tuwak which is also known as Tuwak City and Guardian Earth, has a variety of potentials to be preserved and introduced to the wider community so that Tuban's own cultural heritage does not stop. In addition, it also serves as an insight to the Tuban youth about the noble spirit that is the hallmark of the Tuban community. The spirit of fairness means the spirit to continue to preserve the potential, culture, and art that has been created from hundreds of years ago which is also one of the legends of the island of Java. Because Tuban itself is a city that has a lot of potential in terms of religion, history and culture. Therefore, branding for Tuban Regency is needed so that the potential can be recognized and preserved. With this City Branding, Tuban has the opportunity to introduce its potential, and also to preserve the country's cultural heritage for its successors. The research method carried out in City Branding uses qualitative methods with a direct approach to the field and distributing questionnaires to relevant parties to deepen knowledge about the city of Tuban itself, observation and in-depth interviews. From this method it can be seen that Tuban is one of the cities in East Java which is rich in potential.
\end{abstract}

Keywords: Potential, Spirit, Culture, Branding, Tuban

\section{PENDAHULUAN}

City branding adalah masalah kontemporer yang semakin penting dan menjadi sebuah kompetisi antara kota-kota lainnya. Hal ini meliputi tempat yang akan dijadikan sebagai lokasi bisnis, tujuan wisata atau tempat tinggal. Sebagaimana dikatakan Kavaratzis, "pada awalnya terletak dari kesadaran bahwa semua pertemuan dengan kota terjadi melalui persepsi dan gambar". Menurut Charles Wrench, "apapun persiapan mental yang kamu bangun merupakan persepsi diri kita dimata orang lain". Orang dapat menghubungkan citra kota dengan sejarah tertentu, dan seiring waktu kota tersebut dapat mengembangkan keunikan tersendiri bagi mereka sehingga hal itu dapat menjadi ciri khas akibat dampak dari globalisasi.

Sedangkan menurut Konsultan pemasaran sekaligus Founder Markplus Hermawan Kertajaya, mengatakan city branding merupakan autentitas dari suatu kota dan hendaknya dikelola dengan baik, diaplikasikan dan menjadi culture serta prilaku, baik aparatur maupun warga kota. Untuk memenuhi kriteria dalam penilain city branding sendiri yaitu dengan (Juanim \& Rahmawati, 2015): 


\section{Attributes}

yaitu mampu menggambarkan sebuah karakter, daya tarik, gaya, danciri khaskota

\section{Message}

Yaitu menggambarkan pesan secara pintar dan mudah atau selalu diingat

\section{Differentiation dan ambassadorship} yaitu memberikan kesan positif, berbeda dengan kota laindan menginspirasi orang untuk datang dan ingin tinggal di kota tersebut

Kabupaten Tuban adalah salah satu kabupaten di Jawa timur yang terletak di Pantai utara jawa timur. Kata Tuban sendiri mempunyai sejarah yang unik. Tuban adalah gabungan kat yang berasal dari Bahasa jawa, yaitu metu banyune (meTU BANyune). Kata tersebut dipercaya orang-orang muncul pada zaman Majapahit. Diceritakan ada seseorang sedang membuka hutan dan heran karena dia menemukan banyak sumber air. Disana, sumber air mengalir deras besar maupun kecil tanpa perlu menggali. Kabupaten Tuban juga terletak di letak yang strategis, yakni perbatasan antara Jawa timur dan Jawa tengah. Dengan begitu Tuban pada zaman dahulu dijadikan tempat pelabuhan utama kerajaan Majapahit dan menjadi salah satu pusat penyebaran agama Islam oleh Walisongo di Jawa timur.

Tuban terkenal dengan slogan kotanya yang sekarang yaitu Tuban Bumi Wali. Terdapat juga julukan lain yang dimiliki oleh Tuban, yaitu Bumi Ronggolawe, Kota Tuak dan Kota Seribu Goa. Dijuluki Bumi Wali karena Tuban dulunya merupakam salah satu pusat penyebaran Islam terbesar yang ada di Indonesia. Bumi Wali adalah sebutan yang berikan kepada suatu wilayah atau tempat yang di dalamnya terdapat sejarah signifikan tentang proses penyebaran Islam di Nusantara khususnya Jawa, nama ini dinisbahkan kepada suatu wilayah, melihat beberapa bukti yang terdapat, seperti makam para wali, yakni makam walisongo dan para muridnya, petilasan, dan beberapa peninggalan yang dinilai ada hubungannya dengan perjuangan para wali saat penyebaran Islam. Salah satu wali yang menyebarkan agama Islam di Tuban adalah Sunan Bonang. Pengaruh Islam yang kuat di masyarakat Tuban masih melekat di kota tersebut. Hal tersebut bisa dilihat dari peninggalan islam yang sampai sekarang masih ada dan dijaga dengan baik di kota tersebut, seperti Masjid Agung kota Tuban. Dalam kehidupan sehari-hari masyarakat juga memiliki budaya yang sampai saat ini masih di gelar oleh pemerintah setempat, yaitu pengajian akbar. Pengajian akbar adalah kegiatan masyarakat Tuban yang biasanya mengundang pembicara ternama untuk melakukan ceramah atau dakwah. Kegiatan biasa dilakukan dalam rangka memperingati momen tertentu. Misalnya, Haul Sunan Bonang, Harlah NU dan lain-lain. Seiring berjalannya waktu, kegiatan ini menjadi kebiasaan yang rutin diadakan oleh pemerintah setempat.

Selain dari sisi religinya, Tuban sebenarnya juga memiliki potensi-potensi akan sejarah maupun kesenian budayanya. Terbukti pada zaman kerajaan Majapahit, Ronggolawe merupakan salah satu yang membantu Raden Wijaya pada waktu pertama kali membangun kerajaan Majapahit. Ronggolawe juga dikenang akan keberaniannya dan pekerja keras yang sampai saat ini melekat pada masyarakat 
Tuban. Sejarah Ronggolawe saat ini kurang diketahui orang masyarakat diluar Tuban. Begitupula dengan sisi kebudayaannya, seperti Sandur yang merupakan merupakan kesenian di Tuban yang sudah seharusnya menjadi warisan budaya di Indonesia dan menjadi potensi Tuban. Sandur adalah jenis kesenian teater tradisional yang populer di Kabupaten Bojonegoro dan Kabupaten Tuban. Sandur berbentuk drama tari dengan mengambil cerita lokal. Secara umum, kesenian teater ini tidak berbeda dengan teater tradisional lainnya yang bersifat sederhana dalam penyajiannya.

Terdapat salah satu kerajinan seni yang menjadi khas kota Tuban sejak zaman dahulu, salah satunya Batik Gedog Tuban yang merupakan salah satu hasil karya budaya bangsa yang berasal dari kabupaten Tuban, Jawa Timur. Terkenal dengan cara pembuatannya yang berbeda dengan batik lain, yaitu dengan cara menulis atau yang biasa disebut batik tulis Gedog. Namun, nyatanya batik Gedog ini merupakan satu dari beragam hasil warisan budaya bangsa yang hampir punah. Nama Gedog berasal dari bunyi dog-dog yang bersumber dari alat penenun batik. Perajin batik di Tuban, secara turun temurun membatik pada kain tenun dan untuk membedakan antara batik dengan kain batik yang lain dan juga berasal dari daerah lain, maka istilah 'gedog' pun dipakai, bersanding dengan kata 'Tuban'. Hal tersebut dikarenakan batik Gedog ini berasal dari Tuban, Jawa Timur.

Tujuan dari City Branding ini adalah untuk mengangkat potensi-potensi yang ada di Tuban yang belum di ketahui oleh khalayak umum, karena City branding yang mengangkat dan mengembangkan ciri khas kota sebagai nilai jual yang tinggi, dapat meningkatkan kesan yang menarik dari sebuah kota untuk memperoleh sumberdaya potensial yang mampu mendorong perkembangan kota (Hidayana, 2016).

Dalam membuat konsep city branding ini banyak aspek yang menentukan keefektifan dari branding itu sendiri, seperti yang dikatakan Simon Anholt (2007, 59-61) yang menciptakan Branding Hexagon untuk mengukur efektivitas city branding menggunakan, yang mana di dalamnya terdapat enam aspek dalam pengukuran efektivitas city branding terdiri atas, Presence (kehadiran), Potential (potensi), Place (tempat), People (orang), Pulse (semangat), Prerequisite (prasyarat). Makadari itu konsep branding city ini juga bertujuan membangun citra dan presepsi yang ada di kota Tuban bahwa masih banyak hal-hal unik dan menarik yang belum diketahui secara luas oleh masyarakat luar tuban. Dalam branding Tuban yang sekarang, yaitu "Bumi Wali" adalah salah satu branding yang hanya menonjolkan salah satu sisi dari potensi yang dimiliki Tuban, "Disini brand Tuban telah terbentuk, publik yang mendengar Kota Tuban, maka yang diingatnya dan yang ada di dalam benaknya adalah tempat wisata religi" (Suhartini 2015). dan itu menjadi salah satu permasalahan yang ada pada Tuban, karena apabila Tuban hanya mengangkat satu potensi saja yaitu religiusnya, Tuban akan berat bersaing dengan tetangga sekitarnya seperti Lamongan atau Jombang yang mempunyai sisi religius yang kuat juga, dan branding "Bumi Wali" ini juga dirasa sudah mulai tidak cocok untuk Tuban, karena Tuban juga mempunyai banyak potensi selain dari sisi religiusnya saja, diantaranya 
adalah dari sisi Budaya dan Sejarah. Tari Sandur adalah salah satu kebudayaan asli Tuban yang berupa drama tari yang mengambil dari cerita lokal dan dibawakan dengan penyajian yang cukup sederhana. Banyak pula tempat wisata yang ada di Tuban yang mengandung sejarah dan budaya, seperti "Pantai Boom sebagai wisata bahari dikarenakan adanya keunikan dan keindahan obyek wisata tersebut, keunikan dapat dilihat dari sejarah keberadaan Pantai Boom dan keindahan panorama alam yang dimiliki." (AB Wicaksono 2015). Selain itu adapula Klenteng Kwan Sing Bio yang dulunya juga merupakan tempat pemujaan kecil milik keluarga berkebangsaan China yang merantau ke Indonesia. Maka dari itu Tuban memerlukan re-branding

\section{METODE PENELITIAN}

Dalam perancangan Re-branding Kabupaten Tuban, metode penelitian yang digunakan terbagi menjadi beberapa tahapan serta teknik analisa yang digunakan. Tahapan penelitian adalah tahapan pengumpulan data yang nantinya data tersebut akan menjadi penentuan visual re-branding dari Kabupaten Tuban. Tahapan pengumpulan data meliputi pengumpulan data kuantitatif dan pengumpulan data kualitatif. Untuk teknik analisa yang digunakan berupa analisa taksonomi.

\section{Metode Pengumpulan Data}

1. Observasi dilakukan untuk mengumpulkan data secara langsung di lapangan.Data tersebut dikumpulkan sebagai dokumentasi data di lapangan. Kegiatan observasi ini juga berguna untuk menambah data mengenai kota terkait.
Karena dapat secara langsung melihat keadaan lapangan bagaimana keadaan lingkungan, sosial, dan masyarakat. Selama observasi dapat juga mencatat atau mengumpulkan sejumlah data dengan menulis singkat bagian terpenting yang akan dan sudah diobservasi.

2. Kuisioner menjadi langkah selanjutnya dalam pengumpulan data kali ini.Pada tahap ini peneliti membuat dua kuisioner yang berbeda tujuannya, yaitu kuisioner internal dan kuisioner eksternal.Kuisioner internal dilakukan secara langsung dilapangan guna mendapatkan data secara langsung yang berasal dari masyarakat di Kabupaten Tuban.Data terkait meliputi pengetahuan sejarah dan budaya yang ada di Kabupaten Tuban.Kuisioner eksternal (AIO) dilakukan secara daring menggunakan google form. Tujuan kuisioner ini guna mendapatkan data yang ditujukan kepada masyarakat luar Kabupaten Tuban.Data terkait meliputi bagaimana penilaian Kabupaten Tuban dimata masyarakat luar.

\section{Teknik Analisa Data}

Teknik analisa data yang digunakan yaitu analisis taksonomi. Pada tahapan analisis taksonomi, masing-masing potensi yang ada di Kabupaten Tuban dipilah satu per satu lalu diperinci menjadi sub-domain hingga tidak ada yang tersisa (exhausted). Tahapan analisis ini berguna untuk memperoleh pemahaman lebih dalam mengenai potensi yang ada di Kabupaten Tuban secara rinci. Pengumpulan dilakukan secara terus menerus melalui pengamatan dan dokumentasi guna mendapatkan banyak data. Dan hasil yang diperoleh dapat 
ditampilkan dalam bentuk diagram kotak, diagram garis dan diagram simpul.

\section{HASIL DAN PEMBAHASAN}

\section{Kekayaan dan Keunikan dari Kabupaten Tuban.}

Kabupaten Tuban merupakan salah satu Kabupaten yang ada di Jawa Timur yang memiliki kekayaan potensi yang beragam, hal ini dapat terlihat dalam berbagai macam potensi alam, budaya dan sejarah, masyarakat, dan religi. Berbagai macam potensi yang dimiliki, mendapat pengaruh dari sejarah yang ada di Kabupaten Tuban dan pengaruh geografisnya. Karena letak geografis yang strategis, daerah ini memiliki banyak sekali keuntungan dalam potensi wisata alam yang dimilikinya. Kabupaten Tuban memiliki banyak sekali wisata alam yang unik sehingga menjadi salah satu destinasi wisata yang direkomendasikan ketika berkunjung kemari. Kemudian, banyaknya peninggalan sejarah dan budaya yang berkaitan dengan Kerajaan Majapahit membentuk sebuah karakteristik yang unik dari masyarakat Tuban. Salah satu karakteristik yang dimiliki masyarakat Tuban adalah sifat adi luhungnya. Hal ini sesuai dengan banyaknya kesenian dan budaya yang bermutu tinggi tetap terjaga dan dilestarikan oleh masyarakat sekitar.

Berbagai macam potensi yang ada di daerah ini dapat menjadi daya tarik dari Kabupaten Tuban. Sektor budaya dan sejarah di Kabupaten Tuban menjadi potensi yang perlu dikembangkan di Kabupaten Tuban. Karena, Tuban memiliki keunikan yang sangat identik dengan unsur budaya dan sejarahnya, dari segi aspek mata pencaharian masyarakatnya, kehidupan masyarakatnya, dan kebiasaan atau adat yang dijalankan hingga saat ini masih berkaitan erat dengan budaya dan sejarah yang dimiliki oleh Kabupaten Tuban. Dapat dibilang bahwa semua aspek kehidupan yang ada di sini, berkaitan erat dengan sejarah dan budaya yang masih terasa hingga saat ini.

Menurut data yang didapat dari pengumpulan data seperti observasi dan kuisioner, dapat dijelaskan bahwa ikon budaya yang mewakili Tuban adalah Batik Gedognya. Karena didalam batik tersebut menggambarkan kekayaan yang dimiliki oleh Tuban. Terdapat salah satu kerajinan seni yang menjadi khas kota Tuban sejak zaman dahulu, salah satunya Batik Gedog Tuban yang merupakan salah satu hasil karya budaya bangsa yang berasal dari kabupaten Tuban, Jawa Timur. Terkenal dengan cara pembuatannya yang berbeda dengan batik lain, yaitu dengan cara menulis atau yang biasa disebut batik tulis Gedog. Namun, nyatanya batik Gedog ini merupakan satu dari beragam hasil warisan budaya bangsa yang hampir punah. Nama Gedog berasal dari bunyi dog-dog yang bersumber dari alat penenun batik. Perajin batik di Tuban, secara turun temurun membatik pada kain tenun dan untuk membedakan antara batik dengan kain batik yang lain dan juga berasal dari daerah lain, maka istilah 'gedog' pun dipakai, bersanding dengan kata 'Tuban'. Hal tersebut dikarenakan batik Gedog ini berasal dari Tuban, Jawa Timur.

Selain itu, Kabupaten Tuban juga memiliki cerita sejarah yang unik mengenai awal mula Kabupaten Tuban pada masa Kerajaan Majapahit yaitu sejarah dari Ronggolawe. Ronggolawe merupakan salah satu yang membantu Raden Wijaya pada waktu pertama kali membangun kerajaan 
Majapahit. Ronggolawe juga dikenang akan keberaniannya dan pekerja keras yang sampai saat ini melekat pada masyarakat Tuban. Sejarah Ronggolawe saat ini kurang diketahui orang masyarakat di luar Tuban.

\section{Pengembangan Analisis Taksonomi dan Konsep Perancangan Re-branding}

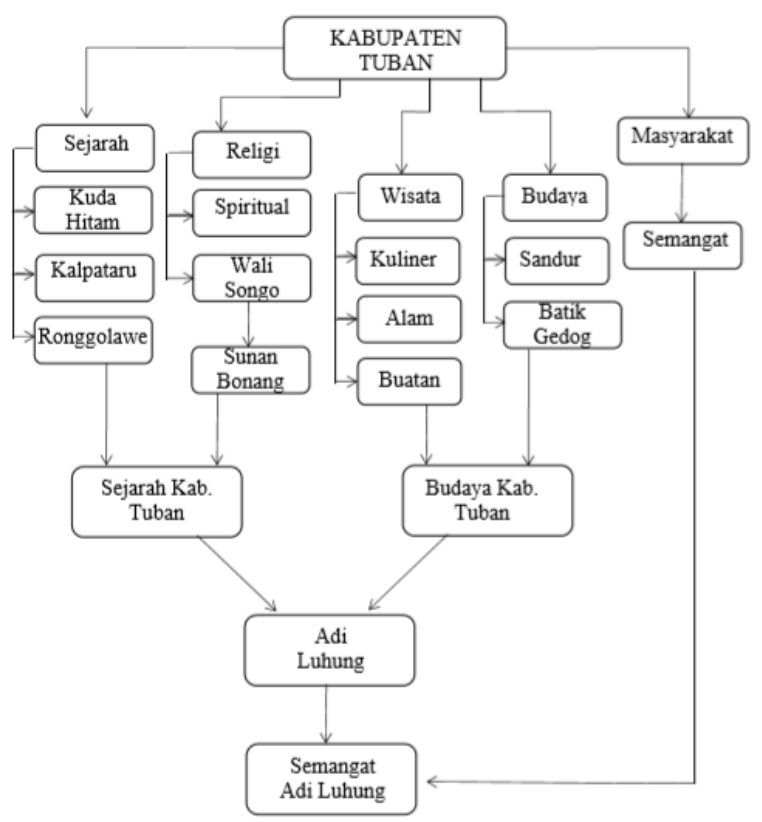

Gambar 1 Analisa Taksonomi City Branding Kabupaten Tuban

(Sumber: Dokumen Pribadi, 2020)

Kabupaten Tuban memiliki 5 domain yang nantinya dapat dikembangkan. Kelima domain tersebut adalah sejarah, religius, wisata, budaya, dan masyarakat. Dalam pengembangan Analisis Taksonomi hal yang dilakukan adalah menganalisa keunikan yang dimiliki oleh Kabupaten Tuban, serta permasalahan apa saja yang yang muncul dalam setiap domain tersebut. Dari kelima domain yang telah disebutkan, kelima hal tersebut menjadi potensi utama untuk menarik wisatawan dan juga menjadi pembeda dari Kabupaten Tuban dalam bidang sejarah, budaya dan masyarakatnya.

Melalui analisa taksonomi dari sejarah, budaya dan masyarakatnya yang tertera diatas, maka dapat ditarik sebuah konsep yang nantinya akan diangkat menjadi sebuah konsep perancangan. Sejarah dan budaya yang identik dengan masa lalu sedangkan masyarakat dapat dikaitkan dengan kebiasaan atau pola kehidupan seseorang, maka ketiga hal tersebut dapat dikembangkan menjadi konsep Re-branding untuk Kabupaten Tuban berupa konsep "Semangat Adi Luhung". Adanya penggabungan antara sejarah, budaya dan masyarakat menjadi landasan dari konsep perancangan Re-branding Kabupaten Tuban. Konsep yang diangkat ini akan menjadi sebuah citra atau wajah baru bagi City Branding Kabupaten Tuban. Citra atau wajah baru ini diharapkan dapat melekat di benak masyarakat Kabupaten Tuban dan wisatawan yang akan datang berkunjung kemari. Dengan konsep "Semangat Adi Luhung", Kabupaten Tuban dapat membuat citra baru yang sangat menggambarkan karakteristik Kabupaten Tuban agar dapat dikenal dikancah nasional maupun Internasional.

\section{Konsep Verbal}

Melalui metode-metode yang telah dilakukan dalam memperkuat suatu identitas dari kota Tuban, lahirlah sebuah tagline yang berguna untuk menjelaskan secara garis besar mengenai kota tersebut. tagline dalam $\mathrm{b}$ beberapa hal, digunakan untuk memposisikan kembali suatu merek (brand). Maksudnya adalah merek (brand) dianggap perlu mengkomunikasikan perasaan-perasaan positif kepada konsumen mereka. Dan dengan tagline 
"Unexpected Treasure of East Java" ini memiliki arti jika Tuban merupakan kota yang penuh dengan potensi yang jarang diketahui oleh banyak orang. Arti dari unexpected treasure sendiri yaitu harta karun yang tidak terduga, yang mana menginterpretasikan jika Tuban memiliki harta karun yang jarang orang-orang ketahui, dan harta karun tersebut merupakan potensi-potensi yang dimiliki oleh Tuban. Potensi-potensi tersebut diantaranya mengenai sejarah, kebudayaan, religi, dan juga alam. Dan melalui City Branding ini, Tuban memiliki kesempatan untuk membagikan harta karunnya kepada masyarakat.

\section{Konsep Visual}

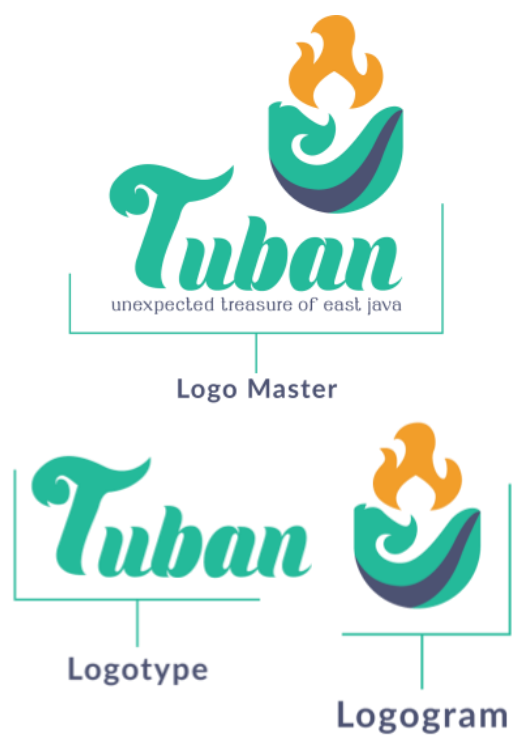

Gambar 2 Logo Kabupaten Tuban. (Sumber: Dokumen Pribadi, 2020)

Untuk memvisualkan citra Kabupaten Tuban maka dibutuhkan adanya Logo City Branding yang bertujuan untuk lebih memperkenalkan dan mempromosikan potensi-potensi yang terdapat di Kabupaten Tuban.
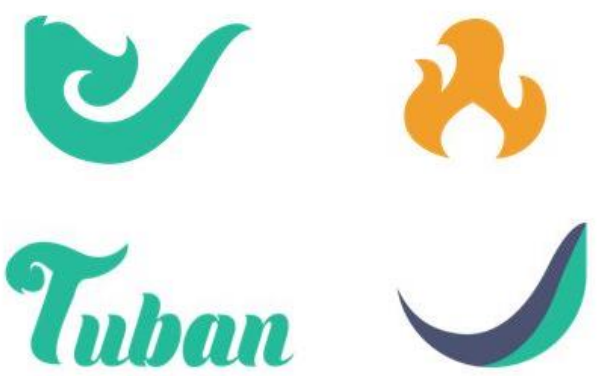

Gambar 3 Makna Logo Kabupaten Tuban. (Sumber: Dokumen Pribadi, 2020)

Makna setiap bentukan logo:

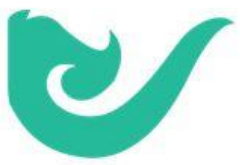

Gambar 4 Makna Logo Kabupaten Tuban. (Sumber: Dokumen Pribadi, 2020)

1. Gambar 4 Adalah bentukan tersebut diambil dari batik Gedog Tuban yang disederhanakan dan menggambarkan kepala kuda.

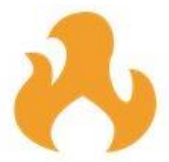

Gambar 5 Makna Logo Kabupaten Tuban. (Sumber: Dokumen Pribadi, 2020)

2. Gambar 5 Bentuk api dan kubah masjid menggambarkan sisi religius dan semangat dalam melestarikan kesenian dan budayanya.

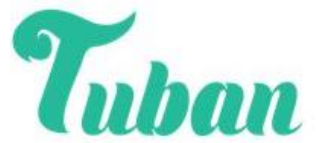


Gambar 6 Makna Logo Kabupaten Tuban. (Sumber: Dokumen Pribadi, 2020)

3. Gambar 6 Motif huruf $\mathrm{T}$ dalam tulisan Tuban diambil dari bentuk logo itu sendiri dan font lainnya menyesuaikan.

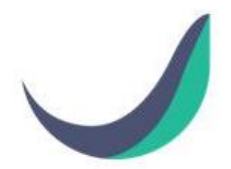

Gambar 7 Makna Logo Kabupaten Tuban. (Sumber: Dokumen Pribadi, 2020)

4. Gambar 7 Terinspirasi dari tangan penari sandur yang lemah gemulai dan disederhanakan.

Visual logo untuk City Branding Kabupaten Tuban memiliki makna semangat dalam menjaga keutuhan seni dan budaya yang ada di Tuban. Logo branding Tuban berupa Logogram dan Logotype. Untuk Logogramnya mengambil dari bentukan kubah dan dikaitkan dengan gambaran api yang menggambarkan semangatnya. Kepala kuda juga menjadi gambaran dalam bentukan logogram ini. Pada keseluruhan bentuknya mengandung unsur motif batik Gedog. Warna yang digunakan dalam logogram ini adalah hijau tosca, biru tua dan oranye. Hijau tosca menggambarkan sisi religius dari Kabupaten Tuban dan juga di kabupaten Tuban sendiri terdapat banyak warna hijau yang menunjukkan asri dan terjaga lingkungannya. Warna oranye berasal dari warna api yang juga menggambarkan semangat masyarakat Tuban dalam menjaga seni dan budayanya.Warna biru menggambarkan warna dari batik Gedog Tuban.

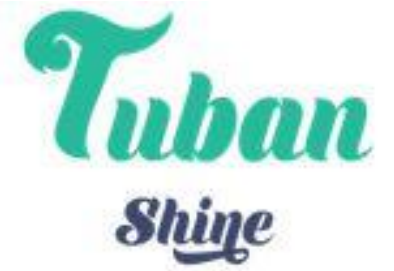

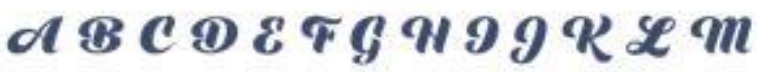

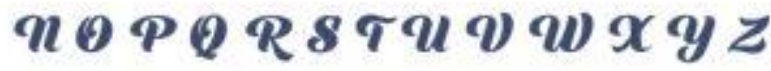
abcdetghijklmnop qustuvixyz

unexpected treasure of east java Rianti-Bold

\author{
A B C D E F G H I K L M \\ NOPQRSTUVWXYZ \\ a b c d e f g h i j k I m n o p \\ qrstu v w x y z
}

Gambar 8 Tipografi pada Logo Kabupaten Tuban. (Sumber: Dokumen Pribadi, 2020)

\section{Penggunaan Font dalam Logotype} Tuban sendiri yaitu serif, karena melambangkan sesuatu yang klasik tetapi juga ada unsur modern di dalamnya, dan pada tagline "Unexpected Treasure Of East Java" memiliki bentuk yang sederhana dan simpel, sehingga memiliki legibility dan readibility yang tinggi.

Jadi dalam penggunaan Logo secara keseluruhan, baik Verbal maupun Visual mempunyai kegunaan yang cukup penting, yaitu untuk memperkuat identitas Tuban sendiri dan dapat memperkenalkan potensi -potensi yang ada pada Tuban kepada 
masyarakat luas, dengan konsep Branding City ini menjadikan Tuban mempunyai ciri khas yang berbeda dari kota-kota yang lain, khususnya di Jawa Timur.

\section{Konsep Media}

Dalam perancangan media ini, perlu upaya sosialisasi dalam waktu yang cukup lama dan terus-menerus agar melekat dalam pikiran dan tindakan. Perlu kerjasama dari seluruh stakeholder. Upaya evaluasi juga harus selalu dilakukan agar dapat ditentukan kebijakan untuk memastikan keberhasilan implementasi city branding (Sardanto 2018), kemudian dalam penjabarannya, dalam merancang konsep media ada 3 tahapan, yaitu tahapan Awareness, tahapan Positioning, dan tahapan reminder. Pada tahapan Awareness ini bertujuan untuk mengenalkan suatu brand agar dapat dikenal dan diingat oleh audiens. Kemudian ada Tahapan Positioning, yang bertujuan untuk menanamkan sebuah citra kepada suatu brand agar dapat melekat di benak audiens dan dapat memaksimalkan potensi yang dimiliki Tuban. Yang terakhir ada Tahapan Reminder, yaitu bertujuan untuk mempromosikan suatu kegiatan yang ada di Tuban dan dilaksanakan rutin untuk mengingatkan audiens secara terus menerus dan agar tertarik kembali ke Tuban.

Tabel 1 Strategi Media City Branding Tuban

(Sumber: Dokumen Pribadi, 2020)

\begin{tabular}{|c|c|c|c|c|c|}
\hline No & $\begin{array}{c}\text { Tahap } \\
\text { Branding }\end{array}$ & $\begin{array}{l}\text { Program } \\
\text { Kegiatan }\end{array}$ & Media & Timeline & Tujuan \\
\hline \multirow[t]{2}{*}{1.} & \multirow[t]{2}{*}{$\begin{array}{l}\text { Awareness } \\
\text { Campaign: } \\
\text { Tuban } \\
\text { mempunyai } \\
3 \text { potensi } \\
\text { utama untuk } \\
\text { menjadi } \\
\text { destinasi } \\
\text { utama } \\
\text { wisata yaitu, } \\
\text { potensi } \\
\text { Religi, } \\
\text { Budaya, dan } \\
\text { Sejarah }\end{array}$} & $\begin{array}{l}\text { Event } \\
\text { Pengajian } \\
\text { Akbar } \\
\text { Tuban }\end{array}$ & $\begin{array}{ll}\text { - } & \text { poster } \\
\text { Pengajian } \\
\text { Akbar Tuban } \\
\text { - Billboard } \\
\text { - Kemasan } \\
\text { oleh-oleh } \\
\text { - Transportasi } \\
\text { Event untuk } \\
\text { Pengajian } \\
\text { Akbar } \\
\text { - Banner }\end{array}$ & $\begin{array}{l}\text { - Bulanan } \\
\text { - Bulanan } \\
\text { - Bulanan } \\
\text { - Tahunan } \\
\text { - Bulanan }\end{array}$ & $\begin{array}{l}\text { Untuk menunjukkan } \\
\text { kepada Audiens } \\
\text { tentang event } \\
\text { Pengajian Akbar di } \\
\text { Tuban ini yang } \\
\text { dilaksanakan secara } \\
\text { rutin, sehingga bisa } \\
\text { menjadi salah satu } \\
\text { pengenalan Tuban } \\
\text { kepada Audiens }\end{array}$ \\
\hline & & $\begin{array}{l}\text { Integrated } \\
\text { Marketing } \\
\text { Communica } \\
\text { tion (IMC) }\end{array}$ & $\begin{array}{l}\text { - Iklan TVC } \\
\text { - Website } \\
\text { - Media } \\
\text { Social } \\
\text { - Merchandise } \\
\text { - Billboard }\end{array}$ & $\begin{array}{l}\text { - } 1 \text { Tahun } \\
\text { - Bulanan } \\
\text { - } \text { Minggua } \\
\text { n } \\
\text { - Bulanan } \\
\text { - Bulanan }\end{array}$ & $\begin{array}{l}\text { Untuk menunjukkan } \\
\text { event yang dimiliki } \\
\text { Tuban dan sekaligus } \\
\text { untuk menarik } \\
\text { Audiens untuk } \\
\text { datang ke Tuban }\end{array}$ \\
\hline
\end{tabular}




\begin{tabular}{|c|c|c|c|c|c|}
\hline \multirow[t]{2}{*}{2.} & \multirow[t]{2}{*}{$\begin{array}{l}\text { Positioning, } \\
\text { membangun } \\
\text { citra brand }\end{array}$} & $\begin{array}{l}\text { Brand } \\
\text { identity } \\
\text { dalam } \\
\text { setiap } \\
\text { sudut } \\
\text { wilayah } \\
\text { yang ada di } \\
\text { Tuban }\end{array}$ & $\begin{array}{l}\text { - EGD : } \\
\text { ○ Sign } \\
\text { System } \\
\text { penunjuk } \\
\text { jalan } \\
\text { O Sign } \\
\text { system pada } \\
\text { fasilitas } \\
\text { umum } \\
\text { o Supergr } \\
\text { afis kota }\end{array}$ & - 5 Tahun & $\begin{array}{l}\text { Sebagai brand image } \\
\text { yang dapat } \\
\text { dirasakan audiens } \\
\text { sehingga akan } \\
\text { tertanam dibenak } \\
\text { mereka }\end{array}$ \\
\hline & & $\begin{array}{l}\text { Menciptaka } \\
\text { n Event } \\
\text { Tahunan, } \\
\text { Festival } \\
\text { Budaya dan } \\
\text { Sejarah } \\
\text { Tuban }\end{array}$ & $\begin{array}{l}\text { - Transpotasi } \\
\text { Event festival } \\
\text { - Agen travel } \\
\text { Event } \\
\text { - Merchandise } \\
\text { - Poster Event } \\
\text { - Billboard } \\
\text { - Media Social }\end{array}$ & $\begin{array}{l}\text { - } 1 \text { Tahun } \\
\text { Sekali }\end{array}$ & $\begin{array}{l}\text { Untuk menarik } \\
\text { Audience agar dapat } \\
\text { ikut serta dalam } \\
\text { event tahunan } \\
\text { Tuban, dan } \\
\text { memberikan } \\
\text { pandangan Audience } \\
\text { tentang Tuban } \\
\text { terkait Event } \\
\text { tahunan yang } \\
\text { diselenggarakan }\end{array}$ \\
\hline \multirow[t]{3}{*}{3.} & \multirow[t]{3}{*}{ Reminder } & $\begin{array}{l}\text { Social } \\
\text { Media } \\
\text { resmi } \\
\text { Tuban : } \\
\text { Unexpected } \\
\text { Treasure of } \\
\text { East Java }\end{array}$ & $\begin{array}{l}\text { - Social Media } \\
\text { (Instagram, } \\
\text { Facebook, } \\
\text { Twitter) } \\
\text { - TVC iklan }\end{array}$ & $\begin{array}{l}\text { - } \text { Tiga } \\
\text { Hari } \\
\text { sekali } \\
\\
\text { - } 1 \text { Tahun }\end{array}$ & $\begin{array}{l}\text { Untuk } \\
\text { mempublikasikan } \\
\text { apa yang sedang } \\
\text { update di Tuban dan } \\
\text { sekaligus } \\
\text { menanamkan ke } \\
\text { benak Audiens } \\
\text { tentang Tuban }\end{array}$ \\
\hline & & $\begin{array}{l}\text { Packaging } \\
\text { kemasan } \\
\text { Oleh - Oleh } \\
\text { Khas Tuban }\end{array}$ & $\begin{array}{l}\text { - Kemasan oleh } \\
\text { - oleh khas } \\
\text { Tuban }\end{array}$ & - 1 Tahun & $\begin{array}{l}\text { Untuk mengingatkan } \\
\text { Audience tentang } \\
\text { keberadaan potensi } \\
\text { Religi, Sejarah, dan } \\
\text { Budaya di Tuban }\end{array}$ \\
\hline & & $\begin{array}{l}\text { Integrated } \\
\text { Marketing } \\
\text { Communica } \\
\text { tion (IMC) }\end{array}$ & - merchantdise & - Bulanan & $\begin{array}{l}\text { Untuk menarik } \\
\text { Audiens untuk } \\
\text { datang ke Tuban }\end{array}$ \\
\hline
\end{tabular}

Media pada tahapan awareness mengacu pada program kegiatan berdasarkan tiga potensi utama yang ada di Kabupaten Tuban melalui strategi Event Pengajian Akbar Tuban dan Integrated Marketing
Communication (IMC). Media tersebut antara lain: Poster pengajian akbar, Billboard, kemasan oleh-oleh, Transportasi Event untuk pengajian akbar, Media Sosial, Iklan TVC Billboard, Website, Media Sosial, merchandise. 

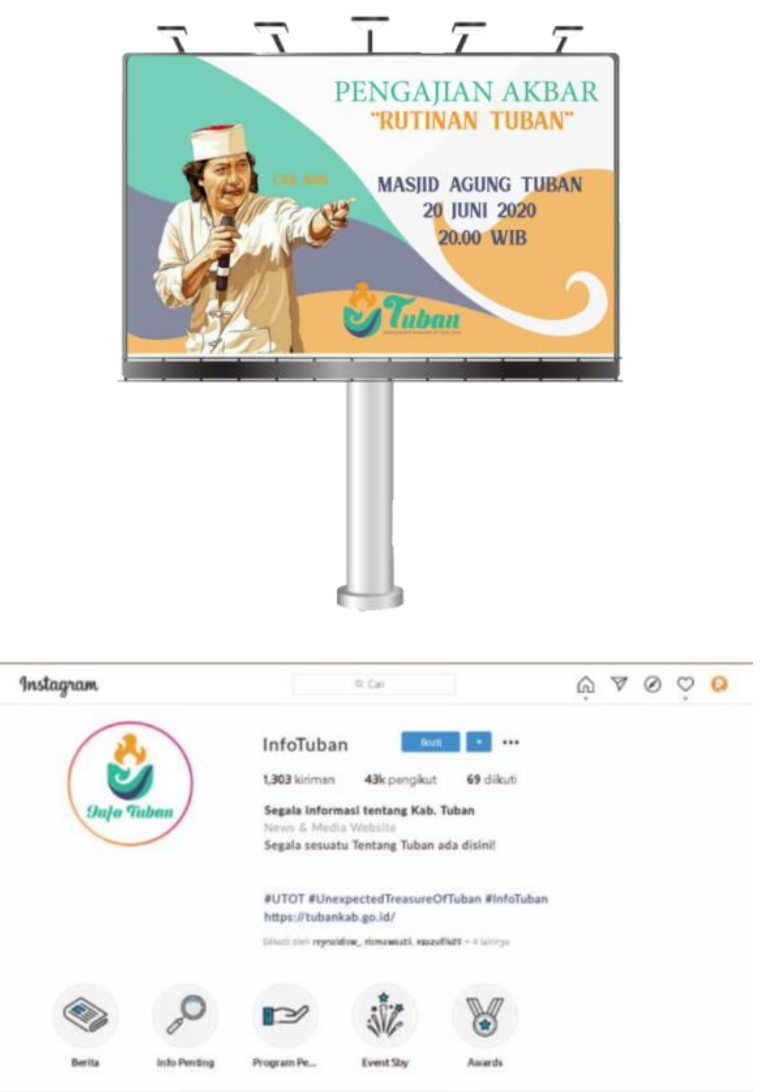

Gambar 9 Contoh Media City Branding pada Tahapan Awareness.

(Sumber: Dokumen Pribadi, 2020)

Media pada tahapan positioning mengacu pada program kegiatan yang bertujuan untuk membangun citra brand Kabupaten Tuban yang memiliki potensi sejarah dan budaya yang beragam. Media yang digunakan antara lain: Enviromental Graphic Design (EGD), Agent event festival, dan Transportasi event festival yang berfokus sebagai brand image untuk ditujukan kepada Audience agar pengalaman berharga tersebut dapat tertanam di benak mereka. Media sekunder seperti Poster event dan merchandise yang bekerjasama dengan agen travel resmi kepada Audience untuk ikut serta dalam event tahunan Tuban, dan memberikan pandangan kepada Audience tentang Tuban terkait Event tahunan yang dimiliki Kabupaten Tuban, Serta media sosial dan billboard yang dibangun untuk menarik wisatawan.
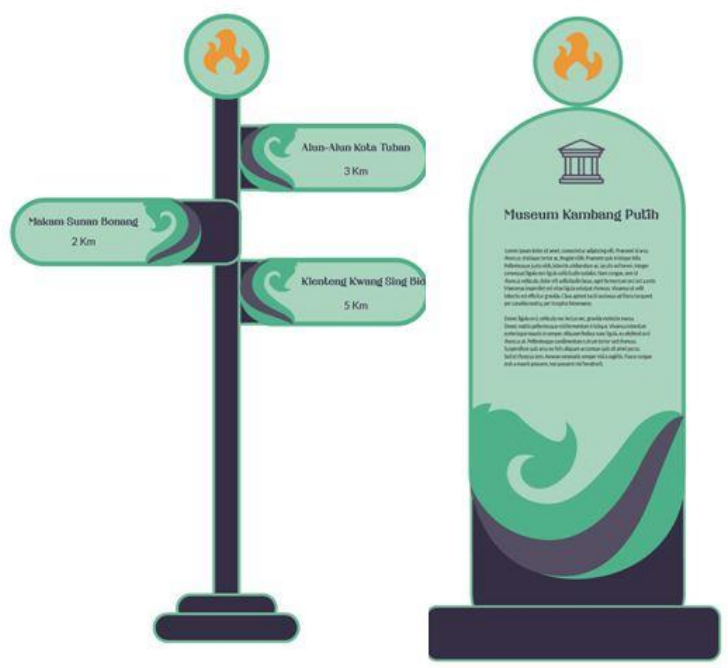

Gambar 10Contoh Media City Branding pada Tahapan Positioning.

(Sumber: Dokumen Pribadi, 2020)

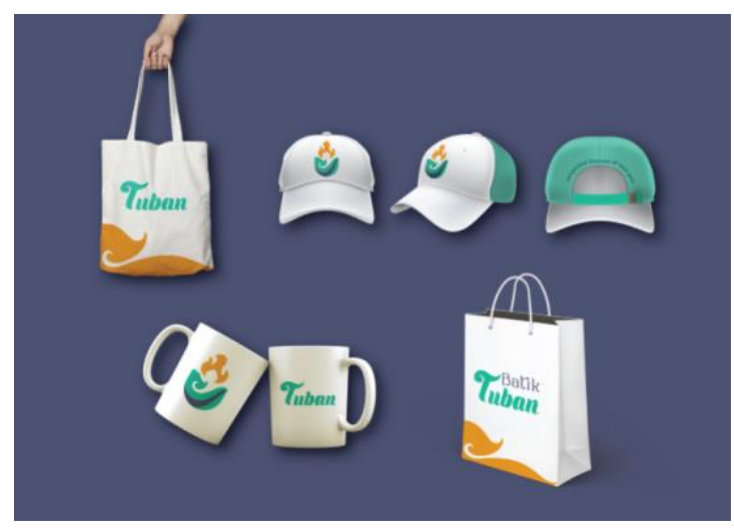

Gambar 11Contoh Media City Branding pada Tahapan Reminder.

(Sumber: Dokumen Pribadi, 2020)

Media pada tahapan Reminder bertujuan untuk mengingatkan kembali kepada Audience mengenaikeberadaan potensi Religi, Sejarah, dan Budayayang dimiliki oleh Kabupaten Tuban. Media Reminder yang digunakan antara lain: Media Sosial, Iklan TVC, merchantdise, dan kemasan oleh-oleh khas Tuban. 


\section{KESIMPULAN}

Kabupaten Tuban memiliki kekayaan potensi yang ada dibidang sejarah, budaya dan masyarakatnya. Peninggalan sejarah dan budaya Kabupaten Tuban yang bernilai tinggi dengan adanya Masjid Agung Tuban, Makam Sunan Bonang, Pantai Boom, Klenteng Kwan Sing Bio, Museum Kambang Putih, Rumah Batik Gedog, dan yang lainnya. Semua kekayaan dan potensi yang ada di Kabupaten Tuban dapat menjadi pintu masuk bagi para wisatawan yang berkunjung ke Kabupaten Tuban.

Konsep yang akan diangkat dalam perancangan Re-branding Kabupaten Tubanini adalah "Semangat Adi Luhung" yang mengangkat mengenai kekayaan sejarah dan budaya yang dipadu dengan semangat dari masyarakat Tuban dalam melestarikan potensi yang ada di Kabupaten Tuban. Berbagai macam kekayaan sejarah, budaya, serta semangat masyarakat yang kemudian dijadikan dalam satu identitas rebranding baru yang menggambarkan Kabupaten Tuban sebagai harta yang tidak terduga dari Jawa Timur. Hal ini diharapkan agar para wisatawan yang kemari, dapat merasakan bahwa Tuban memiliki harta yang tidak terduga karena banyaknya potensi yang dimiliki di daerah ini. Serta, pemilihan tagline "unexpected treasure from East Java" merupakan hasil dari proses pengumpulan data yang kemudian diolah hingga dirasa cocok dengan penggambaran Kabupaten Tuban.

\section{UCAPAN TERIMA KASIH}

Ucapan terima kasih kami sampaikan kepada Pemerintah Kabupaten Tuban yang telah memberikan ijin untuk mengobservasi serta melakukan penelitian untuk merancang Re-branding Kabupaten Tuban. Terima kasih juga kepada petugas Touris Information Center (TIC) Museum Kambang Putih. Terima kasih juga kepada petugas Touris Information Center (TIC) Klenteng Kwan Sing Bio. Terima kasih kepada masyarakat Kabupaten Tuban yang turut serta membantu memberikan informasi mengenai Kabupaten Tuban. Terima kasih kepada tim peneliti atas kerja sama dan kebersamaannya dalam proses perancangan Re-branding Kabupaten Tuban yang telah dilaksanakan.

\section{DAFTAR PUSTAKA}

\section{Buku}

[1] Anholt, Simon. 2007. Competitive Identity: The New Brand Management for Nations, Cities and Regions. USA: Palgrave Macmillan.

[2] Hidayana. (2016). Peran Dinas Pemuda, Olahraga, Kebudayaan, dan Pariwisata Kota mengenai City Branding dalam Menarik Wisatawan di Kota Balikpapan. EJournal Ilmu Komunikasi

[3] Juanim, \& Rahmawati, N. L. (2015). Pengaruh City Branding terhadap Image Of Urban Destination dan Dampaknya pada Post-VisitBehavior. Trikonomika, 14(1), 66-75

[4] Putri, Eka Aulia E. 2016. Senantiasa Di Sisi Anda Sebagai Branding Tagline Dalam Membentuk Citra Terpercaya Nasabah Bank Central Asia (BCA) Samarinda. Samarinda: eJournal Ilmu Komunikasi

[5] Saputra, Irwan Ade. 2014. Buku Saku: City Branding Makassar. Makassar: Vier Antares Institute

[6] Sardanto, Rino. 2018. Membangun Persepsi Publik Tentang City Branding. Kediri: Fakultas Ekonomi Universitas Nusantara PGRI Jawa Kediri 
[7] Schoja, Viktoria. 2016. City Branding: How to Position a City as a Brand. Hamburg: Anchor Academic Publishing

\section{Website}

[1] academia.edu. Penyebaran Islam Di Jawa Dan Masuknya Ke Tuban, Diakses pada 26 April 2020,dari https://www.academia.edu/38169034 /Bab_IV_Penyebaran_Islam_ke_Tuban.p df

[2] bloktuban.com. (2019, Maret 15). Ribuan Warga Hadiri Pengajian Umum Haul Sunan Geseng, Diakses pada 26 April 2020,dari http://bloktuban.com/2019/03/15/ri buan-warga-hadiri-pengajian-umumhaul-sunan-geseng/

[3] Digilib.uinsby.ac.id. (2019, 09 Mei). City Branding Kabupaten Tuban Sebagai Bumi Wali. Diakses pada 27 April 2020,dari https://www.google.com/url?sa=t\&rct $=\mathrm{j} \& \mathrm{q}=\&$ esrc $=\mathrm{s} \&$ source $=$ web $\& \mathrm{~cd}=\& \mathrm{ved}=$ 2ahUKEwipqLjD3NXpAhWabysKHVCD CzEQFjACegQIBRAB\&url=http\%3A\%2F \%2Fdigilib.uinsby.ac.id\%2F3711\%2F3 $\% 2$ FBAB\%2520I.pdf\&usg=AOvVaw3N 075-q-iGSZltOhJTTQuk

[4] indonesiatatler.com. (2019, Juni 21). Batik Gedog Tuban, Warisan Tanah Air Yang Hampir Punah, Diakses pada 26 April 2020,dari https://indonesiatatler.com/artsculture/arts/4-fakta-tentang-batikgedog-tuban-yang-hampir-punah

[5] indonesia.stt-mandala.web.id. Kabupaten Tuban, Diakses pada 26 April 2020,dari http://indonesia.sttmandala.web.id/id1/2517-

2408/Tuban_16195_indonesia-sttmandala.html

[6] irwanadesaputra.files.wordpress.com. Buku Saku City Branding Makassar, Diakses pada 08 Juni 2020,dari radarbojonegoro.jawapos.com. (2020, Februari 29). Semua Kita Rangkul karena Tuban Milik Bersama, Diakses pada 26 April 2020,dari https://radarbojonegoro.jawapos.com/ $\mathrm{read} / 2020 / 02 / 29 / 181550 /$ semuakita-rangkul-karena-tuban-milikbersama

[7] repository.unair.ac.id. (2015, Maret 02). Pengelolaan Obyek Wisata Religi (Studi Deskriptif Pengelolaanobyek Wisata Religi Makam Sunan Bonang Di Kabupaten Tuban. Diakses pada 27 April 2020,dari http://repository.unair.ac.id/18570/

[8] tubancity.com. Ciri Khas Warga Masyarakat Kota Tuban, Diakses pada 26 April 2020,dari https://www.tubancity.com/ciri-khaswarga-masyarakat-kota-tuban.html

[9] tubancity.com. Pengertian Dari Kata Tuban, Diakses pada 26 April 2020, dari https://www.tubancity.com/pengertia n-dari-kata-tuban.html

[10] tubancity.com. Sejarah dan arti kata Kota Tuban, Diakses pada 26 April 2020,dari https://www.tubancity.com/sejarahdan-arti-kata-kota-tuban.html 